\title{
Safe Methods of Radioactive Waste Utilization
}

\author{
Veronika V. Gafarova ${ }^{a, b}$ and Tatiana A. Kulagina*a \\ ${ }^{a}$ Siberian Federal University \\ 79 Svobodny, Krasnoyarsk, 660041, Russia \\ ${ }^{b}$ Mining and Chemical Combine \\ 53 Lenin Str., Zheleznogorsk, 662972, Russia
}

Received 09.04.2016, received in revised form 24.04.2016, accepted 17.05.2016

The results studies of radioactive waste utilization, and the nuclear industry in particular, solidification of liquid radioactive waste of low and medium activity levels. For solid waste, consider the technical means and organizational measures for safe storage. Established and justified allowable the volumes of solid radioactive waste storage the item as a whole and each vault separately, their radionuclide composition, and aggregate allowable specific activity and periods of storage. The method and the experimental results of measuring the power of equivalent dose in the container containing fissile material.

Keywords: solid radioactive waste, dissolution of solid precipitation of nuclear fuel waste, han-dling methods of radioactive waste management, track detector.

\section{Безопасные методы утилизации радиоактивных отходов}

\author{
В.В. Гафарова ${ }^{a, \tilde{,}}$, Т.А. Кулагина ${ }^{a}$ \\ ${ }^{a}$ Сибирский федеральный университет \\ Россия, 660041, Красноярск, Свободныий, 79 \\ ${ }^{\circ}$ Горно-химический комбинат \\ Россия, 662972, Железногорск, Ленина, 53
}

Изложены результаты исследований утилизации радиоактивных отходов в атомной промышленности и, в частности, отверждения жидких радиоактивных отходов низкого и среднего уровней активности. Для твердых радиоактивных отходов рассмотрены технические средства и организационные мероприятия по безопасному хранению. Установлень и обоснованы допустимые объемы ТРО для пункта хранения в целом и каждого хранилищза в

(C) Siberian Federal University. All rights reserved

* Corresponding author E-mail address: tak.sfu@gmail.com 
отдельности, их радионуклидный состав, допустимая суммарная и удельная активность и сроки хранения. Приведены методика и экспериментальные результаты измерения мощности эквивалентной дозы в контейнере с делящимися материалами.

Ключевые слова: твердые радиоактивные отходы, растворение твердых осадков отходов ядерного топлива, методы обращения с радиоактивными отходами, трековый детектор.

\section{Обращение с жидкими радиоактивными отходами}

Проблема радиационной безопасности - одна из социальных проблем современности, решением которой занимаются многие международные, национальные и региональные организации [1]. Развитие атомной промышленности и широкое внедрение источников ионизирующего излучения создают потенциальную угрозу радиационной опасности.

В результате деятельности радиационно и ядерно опасных производств образуются радиоактивные отходы [2]. В систему обращения с радиоактивными отходами заложен основной принцип радиационной безопасности - локализация, удержание и изоляция от окружающей среды.

За период эксплуатации радиохимических производств накоплено значительное количество жидких радиоактивных отходов (ЖРО), для отверждения которых применяются различные методы: битумирование, включение в полимерную матрицу, остеклование, цементирование.

Данные методы направлены на изменение агрегатного состояния и физико-химических свойств радиоактивных отходов и включают следующие технологические операции:

- концентрирование радионуклидов методом упаривания, ионного обмена, сорбции и др.;

- отверждение концентратов;

- частичный возврат очищенных до санитарных норм веществ и материалов, образующихся при переработке ЖРО, для повторного использования в производстве.

Отверждение концентратов радиоактивных отходов осуществляется путем включения их в связующие, которое должно удовлетворять следующим основным требованиям:

- низкая вымываемость, характеризующая высокие изоляционные свойства;

- совместимость с составляющими концентрата отходов, обеспечивающая высокую степень накопления концентрата, следовательно, минимальный объем конечного продукта;

- прочность, исключающая разрушение отвержденного продукта в аварийных ситуациях, при транспортировании (относится к продуктам включения в неорганические матрицы);

- биостойкость (отвержденные продукты не должны подвергаться воздействию бактерий и микроорганизмов);

- радиационная стойкость, определяющая, в частности, газовыделение из отвержденных продуктов;

- простое технологическое оформление процесса отверждения.

Помимо соответствия указанным выше требованиям связующее должно быть сравнительно дешевым, малодефецитным, удобным для транспортировки и производиться в стране [3]. 
Рассмотрим используемые в настоящее время методы отверждения ЖРО.

Битумирование. Представляет собой один из перспективных способов отверждения, уже применяемый во многих странах.

Внедрению процесса битумирования предшествовали работы по изучению влияния состава отходов на процесс и свойства конечного продукта, уточненные в процессе работы опытных установок. Это дало возможность определить оптимальные условия проведения процесса: исключить возникновение экзотермической реакции между нитратом натрия и битумом (температура взаимодействия не выше $350{ }^{\circ} \mathrm{C}$ ) и возгорание битума (возможно лишь при создании сильного теплового воздействия, приводящего к разогреву выше температуры самовоспламенения, т.е. выше $350{ }^{\circ} \mathrm{C}$ ) [4-6].

Битум благодаря своей термопластичности позволяет при нагревании успешно включать в себя концентраты с получением гомогенного продукта. Гидростойкость битума обеспечивает довольно надежную гидроизоляцию включенных компонентов. Отмечается также меньшая чувствительность битума к составу отверждаемого продукта, чем у связующих, включение отходов в которые возможно при комнатной температуре.

Также битумы привлекают внимание такими положительными качествами, как непроницаемость, пластичность, достаточная химическая инертность, невысокая стоимость.

Предельные величины включения отходов зависят от их состава [5]. Ограничивается степень включения гигроскопичных соединений - ионообменных смол (не более $20 \div 30 \%$ ), кристаллогидратов (например, тетрабората натрия не более 20 \%). Фильтроматериалы типа перлита, датолита при включении в битум более $10 \%$ приводят к затвердению битума. Однако

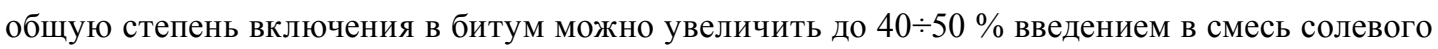
наполнителя, например нитрата или сульфата натрия.

Не рекомендуется подвергать битумированию кислые растворы с большим содержанием нитратов железа и алюминия, которые могут окислить битум, изменяя его термопластические свойства. При битумировании сильнощелочных растворов со значением $\mathrm{pH}$ более 12 может происходить омыление органических соединений, входящих в состав битума, что уменьшает его водоустойчивость.

Исследования влияния радиации на свойства битумированных отходов показали, что при мощности дозы $\gamma$-излучения не более 0,1 Гр/с отсутствует разложение битума, не изменяется фракционный состав и не наблюдается газовыделение при хранении.

В процессе проведенных опытно-промышленных испытаний по обращению с низкоактивными и среднеактивными ЖРО в настоящее время применяется три основных типа установок по битумированию ЖРО:

1. Шнековый смеситель (экструдер) с обогревом паром или органическим теплоносителем, в который непрерывно подаются битум и отходы и непрерывно выгружается готовый продукт. Аппарат не предназначен для упаривания пенящихся растворов и имеет недостаточно развитую греющую поверхность. Шнековый смеситель рационально использовать для предварительного обезвоживания отходов или пульп.

2. Пленочный роторный испаритель позволяет в одном аппарате осуществлять удаление влаги и битумирование. Теплоносителем служит греющий пар, который имеет ограниченные температурные параметры и не допускает температуру внутри аппарата выше $230 \div 240{ }^{\circ} \mathrm{C}$.

$$
-587-
$$


3. Установки периодического действия с внутренними электронагревателями, в котором на порцию горячего битума подаются при постоянном перемешивании механической мешалкой отходы. Недостатки аппарата - малая производительность (не более 70 л/ч), возможность отложения битумных солевых наростов на стенках аппарата, электроподогрев, не исключающий перегрев свыше температуры $200{ }^{\circ} \mathrm{C}$.

Конечные операции на всех установках битумирования одинаковы: затаривание битумной массы, хранение или захоронение контейнеров с продуктами. Для захоронения радиоактивных отходов используют искусственные битумы, получаемые окислением гудрона или других продуктов перегонки нефти кислородом.

К недостаткам данного метода можно отнести неустойчивость битумных блоков при температуре свыше $350{ }^{\circ} \mathrm{C}$. Увеличение содержания солей в битумной смеси может вызвать ее расслаивание в разогретом состоянии при транспортировке или в начальном периоде хранения. Это может привести к разрушению битумных блоков и высвобождению хранящихся в них радионуклидов [7].

Метод полимеризации особенно удобен для фиксации отработавших ионообменников. В отличие от битумирования процесс полимеризации протекает без нагревания. Аппаратура при этом может быть использована та же, что и для битумирования. Полимерные продукты обладают по некоторым параметрам лучшими по сравнению с битумом свойствами. В полиэтилен можно включать до $40 \%$ неорганических отходов (в битуме возможна фиксация до $60 \%$ солей). Стоит отметить, что при содержании в полиэтилене до $40 \%$ солей самовоспламенение происходит при $440{ }^{\circ} \mathrm{C}$, тогда как битумированный продукт с $60 \%$-ным содержанием солей самопроизвольно может загореться при температуре $350{ }^{\circ} \mathrm{C}$. Полимерные материалы можно применять для отверждения отходов с большим содержанием нитритов и нитратов, что невозможно в случае битума. Полимеры обладают хорошей химической стойкостью.

В последнее время перспективным является способ включения радиоактивных отходов в полиэтилен при низких температурах.

Например, в Японии концентрат ЖРО превращают в порошкообразные вещества и после равномерного перемешивания вместе с пластмассой отверждают его в железных бочках. Данный метод уменьшает количество используемых бочек, поэтому обладает лучшей объемной эффективностью [8].

Полиэтиленовые блоки стойки к воздействию ионизирующего излучения, выветриванию, вымыванию водой и пожаробезопасны. Водостойкость отвержденных продуктов достаточно высока и соответствует уровню вымываемости из битумных блоков.

Процесс остеклования отходов происходит с применением высоких температур по сравнению с битумированием, но это компенсируется очевидными преимуществами свойств остеклованных отходов, приводящих к упрощению транспортировки и захоронения (значительное сокращение объема, пожаробезопасность).

Стекло - нестехиометрическое соединение, при нагревании способно растворять, а при последующем охлаждении прочно удерживать сложную смесь оксидов продуктов деления. Получаемый продукт обладает высокой химической и радиационной стойкостью, изотропный, непористый. 
Главный недостаток стекла - его термодинамическая неустойчивость, которая проявляется в кристаллизации стекла (расстеклование) под действием высокой температуры, обусловленной радиоактивным распадом. Расстеклование ухудшает первоначальные свойства продукта, в частности приводит к возрастанию скорости его выщелачивания.

Способ остеклования РАО обеспечивает разложение значительного количества входящих в состав отходов химических соединений, тем самым исключая необходимость учитывать их вредное влияние при захоронении и значительно сократить объем по сравнению с битумированием (в $2 \div 4$ раза).

Недостатком способа остеклования отходов выступает частичное разрушение блоков под действием излучения или перегрева, приводящих к снижению надежности хранения радионуклидов. Для повышения стойкости блоков на них наносят коррозионностойкие материалы, например слой свинца толщиной в несколько миллиметров. Для совершенствования процесса стеклования твердые гранулированные высокоактивные продукты включают в металлическую матрицу. В результате этого улучшается теплоотвод от металлостеклянного материала и повышается теплопроводность блоков (примерно в 10 раз).

В Англии отрабатывали периодический способ остеклования отходов, осуществляемый в тигле, который затем служит контейнером для хранения стекла. В Японии разработан низкотемпературный процесс включения ВАО в боросиликатное стекло. Этот способ, названный низкотемпературным синтезом стекла и осуществленный в лабораторном масштабе, позволяет снизить летучесть радиоактивных веществ и уменьшить коррозию конструкционных материалов аппаратов.

В США изучение процесса остеклования проводят путем плавки в металлической плавильной установке непрерывного действия, в керамической плавильной печи или в тигле, который предполагается затем использовать в качестве контейнера для хранения отходов.

В России для промышленного остеклования жидких ВАО основное распространение получили керамические плавители прямого электрического нагрева.

Так, в «ПО «Маяк» данный способ применяется в промышленном масштабе с 1987 г. Иммобилизация жидких ВАО радиохимического производства в устойчивый матричный материал происходит на неэвакуируемых плавителях прямого электрического нагрева типа ЭП-500. За прошедший период времени на предприятии отработали расчетный срок и были выведены из эксплуатации четыре подобные печи. В результате работы данных печей за 15,3 года (эффективное время эксплуатации оборудования) было отверждено 28600 м $^{3}$ ЖРО с получением 6200 т высокоактивного алюмофосфатного стекла, содержащего радионуклиды, суммарная активность которых составляет около 640 млн Ки [9].

Процесс цементирования используется для жидких радиоактивных отходов низкого и среднего уровней активности с включением ЖРО в неорганические вяжущие.

Образующийся при цементировании продукт обладает целым рядом достоинств: высокой механической прочностью, является негорючим, радиационно и химически устойчив. Высокая плотность цементных материалов способствует уменьшению внешнего излучения.

Основным вяжущим материалом, используемым для цементирования радиоактивных отходов, признан портландцемент (ПЦ), основу которого составляет измельченный клинкер. Качество клинкера определяется его химическим и минералогическим составом. Химический

$$
-589-
$$


состав портландцементного клинкера в основном характеризуется содержанием следующих оксидов:

$\begin{array}{llllll}\mathrm{CaO} & - & \text { от } 64 \text { до } 67 \%, & \mathrm{Na}_{2} \mathrm{O} \text { и } \mathrm{K}_{2} \mathrm{O} & - & \text { от } 0,5 \text { до } 1,0 \% \text {, } \\ \mathrm{SiO}_{2} & - & \text { от } 21 \text { до } 25 \%, & \mathrm{MgO} & - & \text { от } 0,5 \text { до } 5,0 \% \text {, } \\ \mathrm{Al}_{2} \mathrm{O}_{3} & - & \text { от } 4 \text { до } 8 \%, & \mathrm{TiO}_{2} & - & \text { от } 0,1 \text { до } 0,3 \% \text {, } \\ \mathrm{Fe}_{2} \mathrm{O}_{3} & - & \text { от } 2 \text { до } 4 \% & \mathrm{P}_{2} \mathrm{O}_{5} & - & 0,1 \text { до } 0,3 \%\end{array}$

Каждый из указанных оксидов влияет на конечные свойства цемента [9]. Например, повышенное содержание оксида кальция обеспечивает быстрый рост прочности и высокую марку цемента, но в твердом состоянии такой цемент отличается пониженной водоустойчивостью.

Цемент с повышенным содержанием $\mathrm{SiO}_{2}$ характеризуется замедленной скоростью набора прочности в начальный период твердения, но через полгода такой цемент будет иметь высокую прочность и хорошую водо- и сульфатостойкость.

Повышенное (более $8 \%$ ) содержание глинозема $\left(\mathrm{Al}_{2} \mathrm{O}_{3}\right)$ ускоряет твердение цемента в первые часы и сутки, но приводит к снижению морозостойкости, водо- и сульфатостойкости.

Скорость твердения портландцемента также можно увеличить за счет более тонкого помола клинкера. Однако увеличение тонкости помола приводит к росту водопотребности цемента, что неблагоприятно сказывается на прочности и других свойствах цементного камня.

Введение в цемент поверхностно-активных веществ (ПАВ) замедляет скорость его твердения [10].

Таким образом, меняя состав клинкера и используя те или иные добавки, можно регулировать свойства портландцемента.

Цементирование жидких радиоактивных отходов низкого и среднего уровней активности как способ их кондиционирования и подготовки к длительному хранению и захоронению в течение многих лет используется практически во всех развитых странах. Иллюстрацией этого могут служить данные по количеству установок цементирования уже в 1988 г., находившихся в эксплуатации в европейских странах (табл. 1) [11].

Таблица 1. Установки цементирования, находившиеся в эксплуатации в европейских странах в 1988 г.

\begin{tabular}{|l|c|l|}
\hline \multicolumn{1}{|c|}{ Страна } & $\begin{array}{c}\text { Количество } \\
\text { установок }\end{array}$ & \multicolumn{1}{|c|}{ Перерабатываемые РАО } \\
\hline Австрия & 1 & Зола, шламы \\
\hline Бельгия & 2 & Солевые концентраты, шламы, ионообменные смолы \\
\hline Германия & 3 & Солевые концентраты, ионообменные смолы \\
\hline Франция & 8 & Солевые концентраты, шламы, ТРО, фильтры \\
\hline Нидерланды & 3 & Солевые концентраты, шламы, ионообменные смолы \\
\hline Испания & 5 & Солевые концентраты, шламы, ионообменные смолы \\
\hline Швеция & 3 & Солевые концентраты, шламы, ионообменные смолы \\
\hline Швейцария & 3 & $\begin{array}{l}\text { Порошковидные ионообменные смолы, солевые } \\
\text { концентраты, зола сжигания, прессованные ТРО }\end{array}$ \\
\hline Англия & 5 & $\begin{array}{l}\text { Песок и шламы из бассейнов выдержки, ионообменные } \\
\text { смолы, оболочки ТВЭл }\end{array}$ \\
\hline
\end{tabular}


В разных странах используются различные варианты аппаратурного оформления процесса, а именно: смешение в захораниваемой емкости, смешение в емкости с последующей выдачей компаунда в захораниваемый контейнер, смешение ЖРО с вяжущим в потоке. Любому внедрению процесса цементирования предшествует изучение процессов, происходящих при цементировании отдельных видов РАО, и влияние этих процессов на качество конечного твердого продукта, которое должно отвечать определенным требованиям.

При цементировании следует учитывать химический состав радиоактивных отходов. Например, ЖРО, образующиеся при эксплуатации атомных станций, могут содержать бораты, сульфаты, нитраты, оксалаты и другие соли, кроме того, органические соединения в виде ионообменных смол и поверхностно-активных веществ. Жидкие радиоактивные отходы радиохимических предприятий могут содержать нерастворимые гидроксиды, в частности гидроксид железа. Большинство макрокомпонентов радиоактивных отходов не являются инертными наполнителями цементной матрицы, а вступают во взаимодействие с вяжущим материалом, влияя на качество конечного продукта. Поэтому во всех странах изучению механизма взаимодействия ЖРО с матричным материалом и разработке технологических режимов цементирования уделяется большое внимание.

Также одним из важных вопросов утилизации радиоактивных отходов считается их безопасное захоронение.

Наиболее подробно требования к качеству захораниваемых отходов изложены в федеральных правилах США - «Требования к лицензированию захоронения радиоактивных отходов в землю» (“10 CFR Part 61 - Licensing Requirements for Land Disposal of Radioactive Waste”) [12]. Согласно этим правилам основным требованием при захоронении радиоактивных отходов является обеспечение структурной стабильности. В дополнение в США разработаны «Технические положения» (Technical Positions) и «Руководство по регулированию» (Regulatory Guides).

Согласно этим документам каждая комбинация отход/матричный материал должна подвергаться определенным испытаниям. Рекомендованные испытания относятся к следующим свойствам: сопротивление сжатию, устойчивость к выщелачиванию, сопротивление сжатию после иммерсионных испытаний в воде, устойчивость к биоразрушению и радиации, устойчивость к термическим циклам, как и контроль, подтверждающий, что содержание свободной воды в отвержденном продукте не превышает 0,5 \% [12].

Испытания на радиационную и биологическую устойчивость проводятся только в том случае, когда отходы содержат органические продукты, так как $\gamma$-облучение имеет очень малое влияние на цементный материал до относительно высоких доз.

Сопротивление сжатию, равное $0,4 \mathrm{MПа,} \mathrm{принято} \mathrm{исходя} \mathrm{из} \mathrm{механической} \mathrm{нагрузки,}$ которой может подвергаться компаунд в могильнике [12]. Исследование воздействия термических циклов важно для отходов, которые до захоронения будут содержаться в хранилище.

Несколько другие требования к качеству цементных компаундов предъявляются в странах Северного сообщества [13]. В частности, минимально допустимая величина сопротивления сжатию равна 50 кг/см² (4,9 МПа).

$$
\text { - } 591-
$$


Аналогичные требования к качеству цементных компаундов приняты и в Российской Федерации [14]. В качестве критериев качества цементного компаунда выбраны следующие параметры:

- скорость выщелачивания;

- механическая прочность при сжатии;

- радиационная устойчивость;

- морозоустойчивость;

- устойчивость к длительному пребыванию в воде.

Радиационная устойчивость, морозоустойчивость и устойчивость к длительному пребыванию в воде характеризуются пределом прочности при сжатии образцов, прошедших соответствующие испытания. Снижение прочности по сравнению с контрольными образцами, хранившимися в воздушно-влажных условиях, не должно превышать $25 \%$. При этом механическая прочность испытанных образцов не должна быть ниже допустимого предела прочности при сжатии. Допустимые пределы показателей качества цементных компаундов после 28 суток твердения приведены в табл. 2.

Если прочность образцов, выдержанных в течение 28 суток, не достигает 75 \% окончательной прочности компаунда, время их выдержки перед последующими испытаниями должно быть увеличено.

Показатели качества цементных компаундов, такие как выщелачиваемость, механическая прочность, морозостойкость, водоустойчивость, радиационная и биологическая устойчивость, зависят от физических свойств твердого цементного компаунда и химических свойств нуклидов, определяющих их подвижность в матрице.

Исследованию влияния различных факторов на свойства цементных компаундов посвящены работы [15-18].

Следует отметить, что образующийся при цементировании продукт обладает рядом достоинств: высокой механической, радиационной и химической устойчивостью, негорюч.

Использование представленных методов отверждения жидких радиоактивных отходов зависит от многих факторов. При выборе формы захораниваемых отходов следует учитывать не только соответствие ее качества действующим нормативным требованиям, но и экономические факторы [19].

Таблица 2. Допустимые пределы показателей качества цементных компаундов [14]

\begin{tabular}{|c|c|c|}
\hline Наименование показателя & Значение & Метод испытания \\
\hline $\begin{array}{l}\text { Скорость выщелачивания (по Cs-137), г/см².cyт, } \\
\text { не более }\end{array}$ & $1.10^{-3}$ & По ГОСТ 29114 \\
\hline 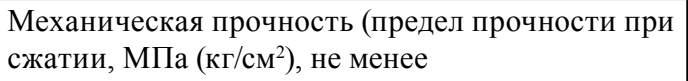 & $4,9(50)$ & По ГОСТ 310.4 \\
\hline Радиационная устойчивость при облучении, Гр & $1.10^{6}$ & $\begin{array}{l}\text { Изменение механической } \\
\text { прочности }\end{array}$ \\
\hline $\begin{array}{l}\text { Морозостойкость (количество циклов } \\
\text { замораживания/оттаивания), не менее }\end{array}$ & 30 & По ГОСТ 100601 \\
\hline $\begin{array}{l}\text { Устойчивость к длительному пребыванию в } \\
\text { воде, сут. }\end{array}$ & 90 & $\begin{array}{l}\text { Изменение механической } \\
\text { прочности }\end{array}$ \\
\hline
\end{tabular}




\section{Обращение с твердыми радиоактивными отходами}

Для твердых радиоактивных отходов (ТРО) также предусмотрены технические средства и организационные мероприятия по безопасному хранению. Установлены и обоснованы допустимые объемы ТРО для пункта хранения в целом и каждого хранилища в отдельности, их радионуклидный состав, допустимая суммарная и удельная активность и сроки хранения.

Одним из параметров контроля в целях обеспечения ядерной и радиационной безопасности при обращении с ТРО является масса накопления делящегося материала (ДМ), для эффективного учета и контроля которой необходимо проводить независимые измерения их изотопного состава. Наиболее часто для этого используют методы неразрушающего анализа (HPA).

Методы НРА подробно рассмотрены в [20], где основное внимание уделяется физическим основам неразрушающего анализа, а также приборному обеспечению. Техническим средствам реализации методов НРА посвящен труд ряда авторов во главе с Д. Райлли [21]. В работе изложена возможность оценки весового содержания ДМ в контейнерах с ТРО по мощности эквивалентной дозы, измеренной вплотную к поверхности контейнера.

\section{Методика и техника эксперимента}

Контейнер вместимостью 3,8 л имеет цилиндрическую форму и оборудован крышками, исключающими возможность радиоактивного загрязнения атмосферного воздуха при транспортировании от места затаривания до места захоронения. Ионизирующее излучение от контейнеров с ТРО возникает в результате $\alpha$-распада ДМ. Внешний радиационный фон создается дочерними продуктами распада, ядра которых, находясь в возбужденном состоянии, испускают гамма-кванты.

Для проведения измерений были использованы следующие средства:

1. Дозиметр рентгеновского и гамма излучения (далее - дозиметр) ДКС - AT1121 или ДКС - АТ1123 с диапазоном измерений мощности дозы гамма-излучения от 50 до 10 Зв/ч.

2. Образцовые источники гамма-излучения типа ОСГИ (далее - источник).

3. Кадмиевый фильтр или кадмиевый пенал толщиной 1 мм.

Фильтр устанавливался под колпачок датчика дозиметра в целях устранения влияния на результат измерения ДМ гамма-излучения от америция-241 с энергией 59 кэВ. Америций-241 возникает в результате $\beta$-распада ДМ. В этих же целях датчик дозиметра помещался в пенал из кадмиевой пластины толщиной 1 мм. Перед началом измерений дозиметр ДКС-АT1121 проверялся по энергетической чувствительности в диапазоне до 800 кэВ с использованием источника бария-133 из набора ОСГИ.

Измерения выполняли, постепенно перемещая датчик дозиметра по поверхности контейнера, до получения максимальных значений мощности эквивалентной дозы (МЭД). В точке максимальных показаний получали $3 \div 5$ результатов измерений на расстоянии 1 см от поверхности контейнера. Каждое измерение МЭД выполняли до получения статистической погрешности $2 \%$. Затем, повернув контейнер на $180^{\circ}$, повторяли измерения в той же последовательности. Результаты измерений МЭД определяли как среднее значение по формуле 


$$
D_{1}=\frac{\sum_{t=1}^{n} D_{i}}{n},
$$

где $D_{i}$ - результат текущего измерения в точке максимальных показаний и в точке с противоположной стороны; $i$ - номер текущего измерения; $n$ - число измерений.

После выполнения измерений МЭД от контейнера, содержащего отходы с ДМ, контейнер был измерен на счетчике нейтронных совпадений для получения точного значения массы ДМ. Всего было измерено 38 контейнеров с ТРО, в которых находился один и тот же ДМ. По результатам измерений методом нейтронных совпадений массы ДМ в контейнере и соответствующих результатов измерений МЭД от контейнера был построен график (рис.) и получена формула, устанавливающая зависимость массы ДМ в контейнере с ТРО от МЭД.

Величина достоверности аппроксимации полученного графика составила $\mathrm{R}^{2}=0,97$.

$$
M_{\text {дМ }}=0,0171 \cdot D^{2}+0,4462 \cdot D+0,0961,
$$

где $M_{\text {дм }}$ - масса ДМ, г; $D$ - среднее значение МЭД от контейнера, мкЗв/ч.

Для проверки полученной градуировочной зависимости был использован государственный стандартный образец (ГСО) ДМ изотопного состава, близкого по составу к ДМ в контейнере. Стандартный образец состоит из корпуса, изготовленного из нержавеющей стали марки 12X18Н10Т, с двумя заваренными крышками, в который помещён ДМ массой 3,2 г. Стандартный образец помещался в центр контейнера объёмом 3,8 л, изготовленного из нержавеющей стали марки 12Х18Н10Т. Получено 15 результатов измерений МЭД в условиях, аналогичных условиям проведения измерений контейнеров с ТРО. Результаты измерений приведены в табл. 3.

В результаты измерений были внесены поправки, учитывающие ослабление измеренных величин МЭД материалом корпуса ГСО, материалом контейнера объёмом 3,8 л, материалом ГСО. Поправка определялась (с учётом толщины стенки корпуса ГСО; толщины стенки контейнера для ТРО; толщины слоя порошка в ГСО, рассчитанной с учётом плотности ДМ) с применением специальной программы MassAttenuationCalculator (MAC) в составе спектро-

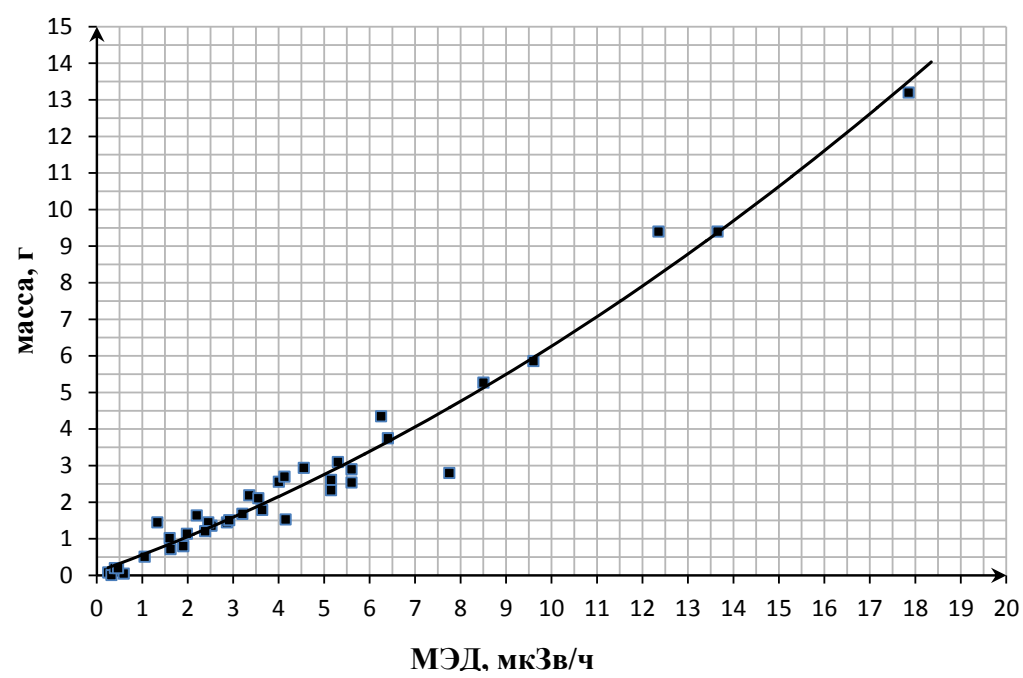

Зависимость массы ДМ от мощности эквивалентной дозы 
метрического комплекса СКС-7П. Поправки на ослабление гамма-излучения составили соответственно 1,260, 1,102, 1,470. По каждому результату измерения МЭД, полученного с учётом поправок, было рассчитано по формуле (2) значение массы ДМ в ГСО. Результаты определения массы в СО приведены в табл. 4.

Для оценки случайной погрешности определяли среднюю квадратичную погрешность результата серии измерений по формуле

$$
\Delta S_{Q \mathrm{cp}}=\sqrt{\frac{\sum_{i=1}^{n}\left(\Delta Q_{i}\right)^{2}}{n \cdot(n-1)}}
$$

где $\Delta Q_{i}=Q_{\mathrm{cp}}-Q_{i}, n$ - количество измерений; $\Delta S_{Q \mathrm{cp}}=0,04$. Доверительную вероятность результатов серии измерений приняли $P=0,95$. Коэффициент Стьюдента для данной доверительной вероятности в зависимости от числа степени свободы $v=(n-1)$, где $n$ - число измерений определяли согласно таблице значений критерия Стьюдента. Для $v=(n-1)=15-1=14$ коэффициент Стьюдента равен $t_{\alpha}(v)=2,1448$.

Границы доверительного интервала абсолютной случайной погрешности определяли по формуле

$$
Q=t_{\alpha}(v) \cdot \Delta S_{Q \mathrm{cp} \cdot}=0,086 .
$$

Относительная погрешность результата серии измерений

$$
E=\frac{Q}{Q_{c p}} \cdot 100 \%=3,14 \%
$$

Относительная суммарная погрешность результата измерения

$$
\delta=\sqrt{E^{2}+\delta_{0}^{2}}, \%
$$

Здесь значение $\delta_{0}$ равно $20 \%, \delta=20,24 \%$

Окончательный результат рассчитали по формуле

$$
\varepsilon=Q_{\mathrm{cp}} \pm \Delta Q=2,74 \pm 0,55 \text {. }
$$

Таблица 3. Результаты измерения МЭД от контейнера с ГСО

\begin{tabular}{|l|c|c|c|c|c|c|c|c|c|c|c|c|c|c|c|}
\hline$№$ измерения & 1 & 2 & 3 & 4 & 5 & 6 & 7 & 8 & 9 & 10 & 11 & 12 & 13 & 14 & 15 \\
\hline МЭД, мкЗв/ч & 2,8 & 2,9 & 2,8 & 2,9 & 2,9 & 3,1 & 3,2 & 3,2 & 3,1 & 3,1 & 3,2 & 3,2 & 3,2 & 3,2 & 3,3 \\
\hline
\end{tabular}

Таблица 4. Результаты определения массы в СО

\begin{tabular}{|l|l|l|l|l|l|l|l|l|l|l|l|l|l|l|l|}
\hline МЭД $а$ рас, мкЗв/ч & 4,52 & 4,7 & 4,52 & 4,7 & 4,7 & 5,02 & 5,18 & 5,02 & 5,02 & 5,18 & 5,18 & 5,18 & 5,18 & 5,18 & 5,35 \\
\hline Масса, г & 2,46 & 2,57 & 2,46 & 2,57 & 2,57 & 2,77 & 2,87 & 2,77 & 2,77 & 2,87 & 2,87 & 2,87 & 2,87 & 2,87 & 2,97 \\
\hline
\end{tabular}


Таким образом, результат измерения массы ДМ в стандартном образце $2,74 \pm 0,55$ не расходится с паспортным значением $2,82 \pm 0,01$.

Данный способ измерения массы ДМ в контейнерах с ТРО является оценочным и позволяет дать первичную оценку весового содержания ДМ в контейнере, сделать выводы о радиационной обстановке, а также обеспечить соблюдение правил ядерной безопасности ПБЯ06-00-96. После этого необходимо провести измерения контейнеров на нейтронном счетчике совпадений для уточнения данных о массе ДМ в данном контейнере.

\section{Список литературы}

[1] Кулагина Т.А., Козин О.А., Матюшенко А.И. Экологическая безопасность техносферHblx объектов: монография. Красноярск: Изд-во «Гротеск», 2015. 323 с. [Kulagina T.A., Kozin O.A. Matiushenko A.I. Environmental safety technospheric objects: Monograph. Krasnoyarsk: Publishing House of the «Grotesque», 2015. 323 p. (in Russian)]

[2] Kulagina T.A., Kozin O.A. Extraction of deposits in enterprises for processing spent nuclear fuel, Chemical and Petroleum Engineering, January 2011. Vol. 46, Issue 9-10, 573-584.

[3] Федеральные нормы и правила в области использования атомной энергии «Сбор, переработка, хранение и кондиционирование жидких радиоактивных отходов. Требование безопасности» НП-019-15: утв. приказом Федеральной службы по экологическому, технологическому и атомному надзору от 25.06.2015 № 242. [The federal rules and regulations in the field of nuclear energy «Harvesting, processing, storage and conditioning of liquid radioactive waste. Safety Requirements» NP-019-15: approved by order of the Federal Service for Ecological, Technological and Nuclear Supervision of 6.25.2015 number 242 (in Russian)].

[4] Соболев А.И., Хомчик Л.М. Результаты эксплуатации опытно-промышленных установок битумирования. М.: Атомная энергия, 1974. [Sobolev A.I., Homchik L.M. The results of operation of pilot plants bituminization. M.: Nuclear Power 1974 (in Russian)].

[5] Кулагин В.А. Методы и средства технологической обработки многокомпонентных сред с использованием эффектов кавитации: дис. ... д-ра техн. наук, Красноярск: КГТУ, 2004, 379 c. [Kulagin V.A. Methods and means of processing multi- media using cavitation effects. Dis. ... Dr. tehn. sciences, Krasnoyarsk : KGTU, 2004, 379 p. (in Russian) ]

[6] Кулагина Т.А. Эффективность подготовительных прочессов сжигания водотопливных смесей в топках малого объема: автореф. дис. ... д-ра техн. наук, Красноярск: КГТУ, 2009, $39 \mathrm{c}$. [Kulagina T.A. The effectiveness of the preparatory process of burning water fuel mixture in the combustion chambers of small volume, Autoabstract diss. ... The doctor tehn. Sciences, Krasnoyarsk: KSTU, 2009, 39 p. (in Russian)].

[7] Ключников А.А., Пазухин Э.М., Шигера Ю.М., Шигера В.Ю. Радиоактивныле отходы АЭС и методы обращения с ними; ред. Ю.М. Шигера. Чернобыль, 2005, 495 с. [Kluchnikov A.A., Pazukhin E.M., Shigeru Y.M., Shigeru V.Y. Radioactive waste nuclear power plants and methods of treatment with them; Ed. Y.M. Shigeru. Chernobyl, 2005, 495 p. (in Russian)].

[8] Андрюшин И.А., Юдин Ю.А. Обзор проблем обращения с радиоактивными отходами и отработавшим ядерным топливом. Саров: ФГУП «РФЯЦ-ВНИИЭФ», 2010, 119 с. [Andryushin I.A., Yudin Yu.A. Overview of treatment problems of radioactive waste and spent nuclear fuel. Sarov: FSUE “VNIIEF", 2010, 119 p. (in Russian)] 
[9] Чистов Ю.Д., Тарасов А.С. Разработка многокомпонентных минеральных вяжущих веществ. Российский химический журнал, 2003. T. XLVII, № 4, 12-17. [Pure Y.D., Tarasov A.S. Development of multi-mineral binders, Russian Chemical Journal, 2003 T. XLVII, N. 4, 12-17 (in Russian)].

[10] Батраков В.Г. Модифицированные бетоныл. М.: Стройиздат, 1990. [Batrakov V.G. Modified concrete. M.: Stroyizdat, 1990 (in Russian)].

[11] Radioactive waste management in Western Europe: a Review, XXIst Unipede International Congress, Sorento, May 29-June 3, 1988.

[12] Thomas Jungling, John Greeves. Nuclear Regulatory Commission. Regulations and Experience with Solidification. Stabilization Technology. American Society for testing and materials, Philadelphia, 1989, 77-82.

[13] Moj Bonnevie-Svendsen, Tollberg K., Aittola P., Tollback H. Studies on the incorporation of spent ion exchange resins from nuclear power plants into bitumen and cement. IAEA-SM-207178, $155-174$.

[14] ГОСТ Р 51883-2002. Отходы радиоактивные цементированные. Общие технические требования. Введ. 2003-01-01. [GOST R 51883-2002. Radioactive waste cemented. General technical requirements. Introduced. 2003-01-01 (in Russian)].

[15] Hideo Matsuzuru, Noboru Moriyama. Leaching of radionuclides from a cement composite incorporating evaporator concentrates generated at a pressurized water reactor Nuclear Power plant. Nuclear Science and Engineering, 1982, v. 80, 14-25.

[16] Lange E., Schlenter W., Laser M. Immobilization of waste-water residues by embedding into concrete. "International symposium on the conditioning of radioactive wastes for storage and disposal", Utrecht, 21-25 Jun. 1982, 155-166.

[17] Je Keun Chon, Kun Jai Lee, W.Me Danial Cement matrix solidification of decontamination ion exchange resin waste. Proceedings of the 1991 joint international waste management conference, vol. 1. Low and intermediate level radioactive waste management, Oct. 21-23, Seoul, 1991, 449-455.

[18] Добшиц Л.М., Соломатов В.И. Влияние свойств цемента на морозостойкость бетонов, Бетон и железобетон, 1999. № 3. 19-21. [Dobshits L.M., Solomatov V.I. Influence of properties of cement on frost resistance of concrete, Concrete and Reinforced Concrete, 1999, N. 3. 19-21 (in Russian)]

[19] Kulagina T.A., Popkov V.A. Industrial and Top Priority Waste Management, Enviromental and engineering aspects for sustainable living: Program, Abstracts IX International symposium Euro-Eco (Hannover, 27-28 November 2014). Germany, Hannover: Europaische Wissenschaftliche Gesellschaft (EWG), Europaische Akademie fur Naturwissenschaften, 2014, 92-94.

[20] Бушуев А.В. Методы измерения ядерныхматериалов. М.: МИФИ, 2007, 276 с. [Bushuyev A.V. Methods of measurement of nuclear materials. M.: MIFI 2007, 276 p. (in Russian)].

[21] Райлли Д., Энсслин Н., Смит Х., Крайнер С. Пассивный неразрушающий анализ ядерных материалов, М.: Бином, 2007. 720 с. [Reilly D., Ensslin N., Smith H., Krainer S. Passive nondestructive analysis of nuclear materials, M.: Binom, 2007. 720 p. (in Russian)]. 